\title{
BMJ Open Adherence and dosing interval of subcutaneous antitumour necrosis factor biologics among patients with inflammatory arthritis: analysis from a Canadian administrative database
}

\author{
Peter Bhoi, ${ }^{1}$ Louis Bessette, ${ }^{2}$ Mary J Bell, ${ }^{3}$ Cathy Tkaczyk, ${ }^{1}$ Francois Nantel, ${ }^{4}$ \\ Karina Maslova ${ }^{1}$
}

To cite: Bhoi P, Bessette L, Bell MJ, et al. Adherence and dosing interval of subcutaneous antitumour necrosis factor biologics among patients with inflammatory arthritis: analysis from a Canadian administrative database. BMJ Open 2017;7:e015872. doi:10.1136/ bmjopen-2017-015872

\section{- Prepublication history for} this paper is available online. To view these files, please visit the journal online (http://dx.doi. org/10.1136/bmjopen-2017015872).

Received 19 January 2017 Revised 7 August 2017 Accepted 8 August 2017

CrossMark

${ }^{1}$ Medical Affairs, Janssen Inc, Toronto, Ontario, Canada ${ }^{2}$ Groupe de Recherche en Rhumatologie et Maladies Osseuses, Sainte-Foy, Quebec, Canada

${ }^{3}$ Department of Rheumatology, Sunnybrook Health Sciences Centre, Toronto, Ontario, Canada ${ }^{4}$ Medical Affairs, Janssen Inc, Toronto, Ontario, Canada

Correspondence to Dr Francois Nantel; fnantel@its.jnj.com

\section{ABSTRACT}

Objectives Subcutaneous tumour necrosis factor alpha TNFoinhibitors (SC-TNFis) such as golimumab (GLM), adalimumab (ADA), etanercept (ETA) and certolizumab pegol (CZP) have been used for many years for the treatment of inflammatory arthritis. Non-adherence to therapy is an important modifiable factor that may compromise patient outcomes. The aim of this analysis was to compare adherence and dosing interval of SC-TNFis in the treatment of people with inflammatory arthritis.

Design We used the IMS Brogan database combining both Canadian private and public drug plan databases of Ontario and Quebec. Target drugs included SC-TNFis for inflammatory arthritis. The index period was from 1 January 2010 to 30 June 2012 and patients were followed for 24 months through 30 June 2014. Inclusion criteria were adult patients newly prescribed a SC-TNFis with at least three prescriptions and retained on therapy at 24 months. Dosing regimens as per the product monographs were used to compare actual versus expected drug utilisation. The mean possession ratio was used as a marker for adherence. Patients who scored $>80 \%$ were considered adherent. The average days between units was estimated by taking the total days on therapy and divided by the number of units the patient received.

Results 4035 patients were included: 683 (16.9\%), 1400 (34.7\%), 1765 (43.7\%) and 187 (4.6\%) were treated with GLM, ADA, ETA and CZP, respectively. The proportion of adherent patients in the GLM cohort $(n=595 / 683,87 \%$, $\mathrm{p}<0.0001$ ) was greater compared with ADA $(n=1044 / 1400$, $75 \%)$, ETA $(n=1285 / 1765,73 \%)$ and CZP-treated patients (132/187, 71\%). In addition, the number of patients receiving biological drug at a shorter dosing interval was similar between cohorts, and was $5 \%, 6 \%, 12 \%$ and $4 \%$ in GLM ( $\leq 26$ days), ADA ( $\leq 12$ days), ETA ( $\leq 6$ days) and CZP-treated patients ( $\leq 12$ days), respectively.

Conclusions In this real-life administrative database, GLM had better adherence compared with other SC-TNFis.

\section{INTRODUCTION}

Inflammatory arthritis (IA), including rheumatoid arthritis (RA), psoriatic arthritis (PsA) and ankylosing spondylitis (AS), is
Strengths and limitations of this study

- The strengths of this study are its large sample size and generalisation since it includes over half of the overall Canadian population of inflammatory arthritis patients.

- Limitations include the absence of clinical data, inability to match cohorts and the potential for administrative coding errors.

- There is also a potential for selection bias since patients had to be on therapy for two years to be included in the analysis.

characterised by severe pain, inflammation, progressive joint damage and decline of physical function over time. More aggressive treatment approaches in the last two decades have led to improved patient outcomes and prevention of disability. The breakthrough in the treatment of IA happened with the introduction of biologics, specifically tumour necrosis factor alpha inhibitors (TNFis) in the late 1990 s and early 2000 s. More recently, biologics with other mechanisms of action were introduced and became available to rheumatologists. ${ }^{12}$ However, TNFis remain the most widely used biologics in rheumatology due to many years of clinical experience and provincial reimbursement criteria in Canada.

However, any treatment, no matter how advanced, would only work if taken by a patient in accordance with the prescription. According to the WHO: 'Across diseases, adherence is the single most important modifiable factor that compromises treatment outcomes'. Indeed, poor adherence to treatment in RA has been shown to have negative impact on patient outcomes. ${ }^{34}$ 
In practice, adherence to treatment reflects the extent to which a medication is taken as prescribed. A number of studies have shown that adherence to treatment is generally poor across chronic diseases: approximately $50 \%$ of all patients with chronic medical conditions do not adhere to their prescribed medication regimens. ${ }^{5}$ In patients with RA, for example, adherence to disease-modifying antirheumatic drugs has been shown to be anywhere from $30 \%$ to $80 \%$, depending on the study and methodology used. ${ }^{6}$ Adherence to biological medications in RA has also shown variability ranging from $11 \%$ to $88 \% .^{7-10}$ The observed differences in results of those studies can be at least partly explained by the absence of a reference standard measure of adherence and wide variability of its definition and terminology. One of the most commonly used measures of adherence is the medication possession ratio (MPR). ${ }^{11}{ }^{12} \mathrm{MPR} \geq 0.8$ (or $80 \%$ ) is a widely used threshold of adherence, ${ }^{13-17}$ though more recent studies suggested that an MPR of $90 \%$ or above may be a better threshold for deeming consumption as 'adherent'. ${ }^{18}$

Several factors can potentially influence patient adherence to therapy, including healthcare system factors (access to therapy), patient-provider relationship, patient-related factors (eg, age, sex, education, socioeconomic status, beliefs about disease and treatment) and therapy-related factors (eg, efficacy, tolerability, convenience, mode/frequency of administration and costs) ${ }^{6}$

All subcutaneous (SC)-TNFis, including golimumab (GLM), adalimumab (ADA), etanercept (ETA) and certolizumab-pegol (CZP), are available in Canada and are approved for the treatment of RA, AS and PsA. The purpose of this analysis was to compare the adherence to treatment and dosing intervals of SC-TNFis among patients with IA.

\section{METHODS}

\section{Data sources}

Data for this analysis was derived from a health administrative database from IMS Brogan, a privately owned company collecting drug utilisation data now part of QuintilesIMS. Those include data from the National private drug plans (PDP) database as well as the public drug plans database for the provinces of Ontario and Quebec (OPDP and Regis de l'Assurance Maladie du Quebec (RAMQ), respectively) in Canada. The data were also completely void of identifying information which precluded the need to obtain ethics approval. The raw data used for this study can be obtained by contacting the owner of the database (IMS Health Consulting). The analysis report used for this manuscript can be provided by communicating with $\mathrm{FN}$.

\section{Patient population selection}

Adult patients (age $\geq 18$ years) starting treatment with one of the SC-TNFis (GLM, ADA, ETA or CZP) from 1 January 2010 to 30 June 2012 for the indication of RA, AS or PsA were identified. Time of initiation treatment with a SC-TNFi served as the index date, and patients were followed up for 24 months. Eligible patients for this analysis were required to remain on the initiated therapy for a minimum of 24 months following the index date. Patients were identified as retained on therapy if the following two criteria were met: patients had at least three prescriptions of a target SC-TNFi and the number of days from the start of the patients first prescription of a target SC-TNFi to the end of the last prescription, including the days of supply of the last prescription, equalled to or exceeded the length of the follow-up period.

\section{Measures}

The recommended dosing regimens for the treatment of IA, as per the Canadian product monographs ${ }^{19-22}$ were used to compare actual versus expected drug use for each SC-TNFi. The dosing regimens for each SC-TNFis are the same between indications and are as follows: $50 \mathrm{mg}$ monthly for $\mathrm{GLM}^{19}$; $40 \mathrm{mg}$ every other week for $\mathrm{ADA}^{22}$ and $50 \mathrm{mg}$ weekly for ETA. ${ }^{21}$ For CZP, the recommended regimen includes a loading dose of $400 \mathrm{mg}$ at weeks 0,2 and 4 and a maintenance dose of either $400 \mathrm{mg}$ every 4 weeks or $200 \mathrm{mg}$ every 2 weeks. ${ }^{20}$ All biologics compared in this study are usually supplied 1 month at a time-GLM is supplied as one dose in a box, ADA as two doses, ETA as four in a box and certolizumab as two in a box.

The compliance rate was calculated by dividing the 'estimated days' supply in the defined period' by the 'number of days in the defined period'. However, 'days' supply' information is not reliable for biological drugs; thus, it was estimated based on total drug use in the defined period. Patients who dose escalated were identified and their days of supply were calculated based on their escalated dosing, so as not to overestimate the adherence. Adherence to a prescribed SC-TNFi was measured by the MPR. ${ }^{11} 12$ Patients who scored $>80 \%$ were considered adherent as per the most commonly accepted definition. ${ }^{14-1623}$

In addition to the unadjusted analyses carried out on the full study population, analyses of adherence were also carried out on cohorts matched by the line of biological therapy, attempting to adjust for potential selection bias. Proportions of patients on first, second, third and fourth line of biological therapy were identified in each cohort. MPR was then calculated based on line of therapy.

For the analysis of dosing interval, the target SC-TNFis were standardised in units based on dosing regimen as per the following: a unit is a syringe or phial; one unit of GLM, ADA, ETA and CZP is $50 \mathrm{mg}, 40 \mathrm{mg}, 50 \mathrm{mg}$ and $200 \mathrm{mg}$, respectively. The total amount of a target SC-TNFi (in $\mathrm{mg}$ ) dispensed per patient was then calculated in units. The average number of days between units was estimated by taking the total days on therapy and dividing by the number of units the patient received.

\section{Statistical analysis}

$\mathrm{p}$ Values obtained from $\chi^{2}$ and pair-wise comparison tests for statistical differences on the proportion of adherent 
Table 1 Medication possession ratio

\begin{tabular}{llllll}
\hline Measure & GLM & ADA & ETA & CZP & $\begin{array}{l}\text { p Value } \\
\text { versus } \\
\text { GLM }\end{array}$ \\
\hline N & 683 & 1400 & 1765 & 187 & \\
MPR, mean & 0.90 & 0.85 & 0.84 & 0.84 & $<0.0001^{*}$ \\
(SD) & $(0.14)$ & $(0.18)$ & $(0.20)$ & $(0.16)$ & \\
MPR $\geq 0.80$, & 595 & 1044 & 1285 & 132 & $<0.0001 \dagger$ \\
n (\%) & $(87 \%)$ & $(75 \%)$ & $(73 \%)$ & $(71 \%)$ & \\
\hline
\end{tabular}

${ }^{*} p$ Value obtained from one-way analysis of variance for multiple means comparison.

tp Value obtained from $\chi^{2}$ and pair-wise comparison tests for statistical differences on the proportion of high adherent patients. ADA, adalimumab; CZP, certolizumab pegol; ETA, etanercept; GLM, golimumab; MPR, medication possession ratio.

patients were carried out. A p value $<0.05$ was considered to be statistically significant.

\section{RESULTS}

The final study population was 4035 patients, including 683 for GLM cohort (16.9\%), 1400 for ADA cohort (34.7\%), 1765 for ETA cohort (43.7\%) and 187 for CZP cohort (4.6\%). The distribution of the study population by data source was as follows: 2509 (62.2\%) from PDP National, 634 (15.7\%) from RAMQ and 892 (22.1\%) from OPDP.

\section{Adherence analysis}

Table 1 provides the MPR measures for each target SC-TNFi. The proportion of adherent patients (MPR $\geq 0.80$ ) was significantly higher for GLM cohort: $87 \%$ versus $75 \%$ for the ADA cohort, $73 \%$ for ETA cohort and $71 \%$ for CZP cohort $(\mathrm{p}<0.0001$ for all cohorts vs GLM). Distribution of patients by MPR within each SC-TNFi cohort is shown on figure 1 . The proportions of patients with the MPR $\geq 90 \%$ were as follows: $70 \%, 54 \%, 54 \%$ and
Table 2 Patient distribution by biological line experience; $\mathrm{n}(\%)$

\begin{tabular}{lclll}
\hline $\begin{array}{l}\text { Index } \\
\text { drug }\end{array}$ & Bionaive (\%) & $\begin{array}{l}\text { Second } \\
\text { line (\%) }\end{array}$ & $\begin{array}{l}\text { Third } \\
\text { line (\%) }\end{array}$ & $\begin{array}{l}\text { Fourth } \\
\text { line (\%) }\end{array}$ \\
\hline CZP & $169(90.4)$ & $16(8.6)$ & $2(1.1)$ & $0(0.0)$ \\
ETA & $1669(94.5)$ & $88(5.0)$ & $7(0.4)$ & $1(0.1)$ \\
ADA & $1322(94.4)$ & $76(5.4)$ & $2(0.1)$ & $0(0.0)$ \\
GLM & $586(85.8)$ & $94(13.8)$ & $1(0.1)$ & $2(0.3)$
\end{tabular}

ADA, adalimumab; CZP, certolizumab pegol; ETA, etanercept; GLM, golimumab.

45\% in GLM, ADA, ETA and CZP cohorts, respectively. The same pattern of results was observed when cohorts were compared by the mean MPR where the GLM cohort had a higher mean MPR $(0.90, \mathrm{p}<0.0001)$ compared with all other cohorts which were similar between each other with a mean MPR of $0.85,0.84$ and 0.84 for the ADA, ETA and CZP cohorts, respectively. Additional analyses were carried out to limit potential biases. Table 2 provides the patient distribution by line of therapy within each target SC-TNFi cohort. The vast majority of patients (between $85.8 \%$ and $94.5 \%$ ) in all treatment cohorts were bionaive with a target SC-TNFi as the first-line biological therapy. However, the proportion of bionaive patients was lower in the GLM cohort $(85.8 \%)$ than in other cohorts $(94.4 \%$ for ADA cohort, $94.5 \%$ for ETA cohort and $90.4 \%$ for CZP cohort). To determine if the line of therapy had an impact on adherence, the proportion of adherent patients (MPR $\geq 0.80$ ) was calculated in the total study population and in cohorts based on the line of biological therapy. The proportion of adherent patients was the same $(76 \%)$, in both the bionaive and bioexperienced cohorts. The analysis was also performed in bionaive patients only, and the results were almost identical to the unadjusted analysis: the proportion of adherent patients (MPR $\geq 0.80$ ) were $88 \%$ for GLM cohort, $75 \%$ for ADA

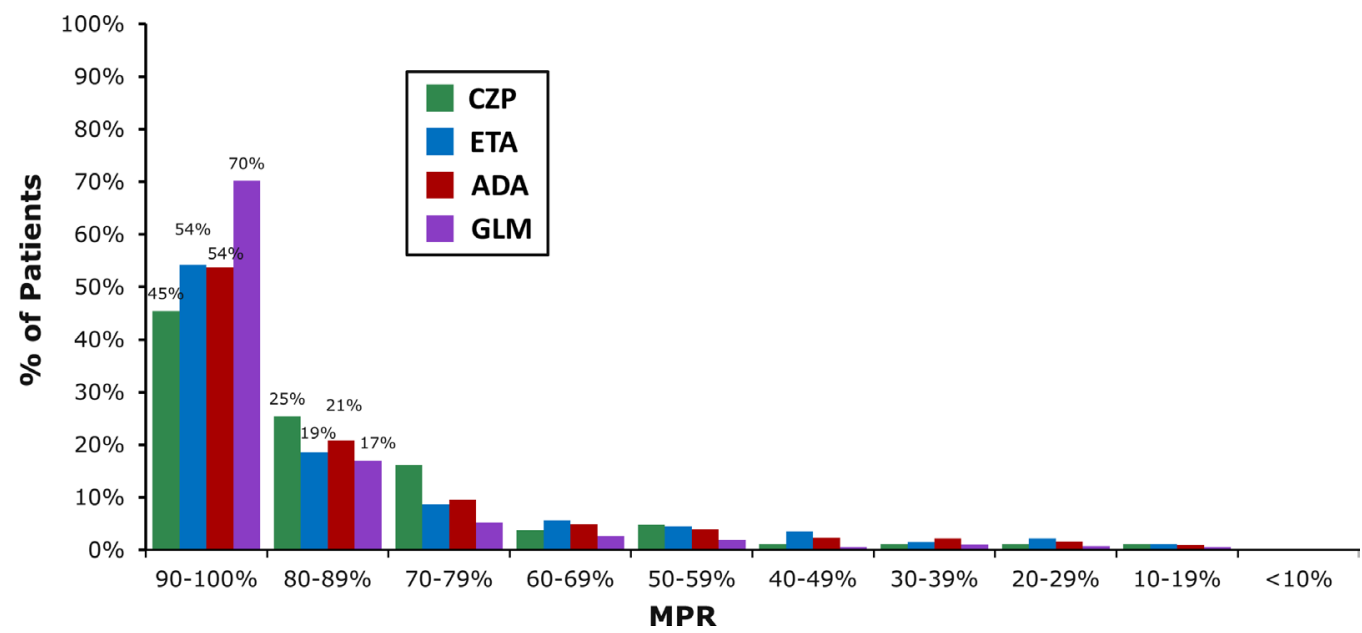

Figure 1 Distribution of patients by MPR within each SC-TNFi cohort. ADA, adalimumab; CZP, certolizumab pegol; ETA, etanercept; GLM, golimumab; MPR, medication possession ratio; SC-TNFi, subcutaneous tumour necrosis factor-alpha inhibitors. 

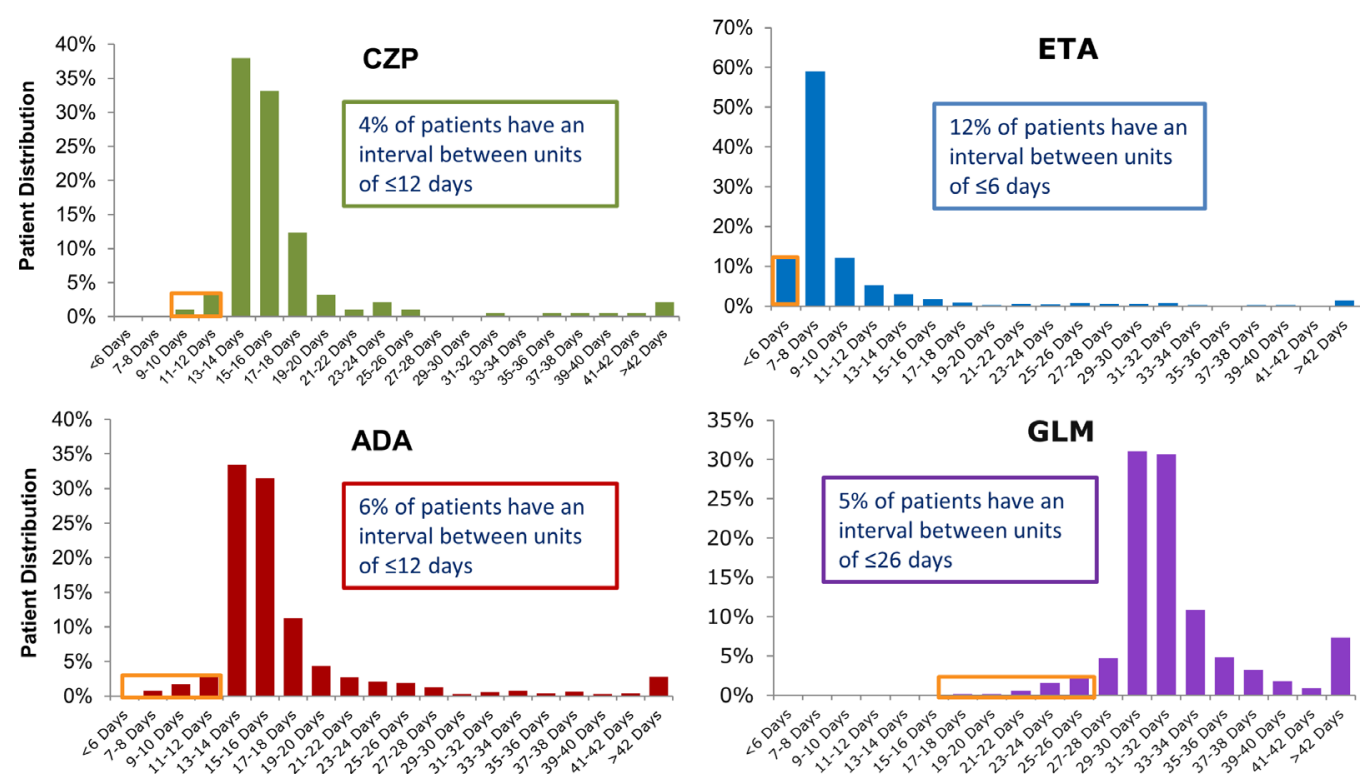

Figure 2 Patient distribution per average days elapsed between units. ADA, adalimumab; CZP, certolizumab pegol; ETA, etanercept; GLM, golimumab.

cohort, $72 \%$ for ETA cohort and $71 \%$ for CZP cohort $(\mathrm{p}<0.0001$ for all cohorts vs GLM).

\section{Dosing interval analysis}

Figure 2 shows the distribution of patients per average days elapsed between units. About two-thirds of patients in each cohort had an average time elapsing between units within the recommended dosing interval \pm 1 day. The remaining third of patients in each cohort had their average dosing interval shorter or longer than recommended by the respective product monographs. To investigate the number of patients receiving their target SC-TNFi more frequently than it is recommended by the product monograph, the following definitions of shorter than recommended dosing interval were assumed based on the dosing regimen for each target SC-TNFi: $\leq 6$ days for ETA (1 day shorter than the recommended regimen of once weekly), ${ }^{21} \leq 12$ days for ADA and CZP (2 days shorter than the recommended regimen of every other week) ${ }^{20} 22$ and $\leq 26$ days for GLM (4 days shorter than the recommended regimen of once monthly). ${ }^{19}$ The proportions of patients in each cohort receiving their SC-TNFi more frequently than recommended by the PM were comparable between the cohorts: $6 \%$ for ADA, $12 \%$ for ETA, $4 \%$ for CZP and $5 \%$ for GLM.

\section{DISCUSSION}

One of the major challenges in the treatment of chronic medical conditions, such as IA, is optimising patient adherence to therapy, as the implications of non-adherence can be far reaching in terms of reducing treatment effectiveness and increasing healthcare costs. ${ }^{3424-27}$ The objectives of this study were to compare the adherence to treatment and dosing intervals of SC-TNFis, including GLM, ADA, ETA and CZP, among patients with IA. The higher proportion of ETA and ADA patients may reflect the fact that GLM and CZP were introduced much later to the Canadian market. Adherence measures were assessed during the study period as well as the dosing intervals.

Overall, we found a considerably high adherence rates to SC-TNFis (76\% of adherent patients), which is in agreement with some of the previous studies of adherence to biologics in RA. ${ }^{70}$ It is possible that this is due to the fact that patient had to be on therapy for 2 years to be included in this analysis. This window was selected to ensure appropriate follow-up time to assess adherence and to remove the potential impact of primary non-response to therapy. Significant differences were identified in adherence measures between the study cohorts. Our analysis showed that GLM patients had significantly higher rates of medication adherence as measured by the mean MPR and proportions of adherent patients (MPR $\geq 80 \%$ ) compared with all other study cohorts.

Those results are in agreement with a US study by $^{10}{ }^{10}$ which compared a number of adherence and use measures in a population of patients with RA starting treatment with a SC-TNFi using deidentified medical information from insurance databases in the USA. Those results were interpreted by the authors as being in agreement with previous findings of patient preferences and better adherence to medications with longer versus shorter dosing intervals ${ }^{28-30}$ and supported the inverse relationship between dosing frequency and adherence reported in various studies with different medication classes. ${ }^{31-33}$ This relationship was also confirmed in our study, as golimumab is the only SC-TNFi on the market with a once-monthly dosing regimen.

Noteworthy, the GLM cohort had a slightly higher proportion of bioexperienced patients comparing to other cohorts in our study, possibly due to its later introduction into the Canadian market and the fact that a trial in TNF failures was available. ${ }^{34}$ Nonetheless, sensitivity 
analyses showed that line of therapy had no impact on adherence.

Dosing interval for SC-TNFis was evaluated in our study with the objective to assess the proportion of patients whose treatment needed to be intensified (ie, by shortening of the dosing interval) during the course of a 2-year follow-up. We found that shortening of the dosing interval was observed in all the SC-TNFi cohorts and that the proportions of patients were comparable between the four drugs. To the best of our knowledge, this is the first detailed report on shortening of the dosing interval across different SC-TNFis. Though a number of studies have reported the dose escalation for SC-TNFis, ranging from $0.4 \%-5 \%$ for ETA and $7 \%-24 \%$ for $\mathrm{ADA},{ }^{35-40}$ comparison with our results would be difficult since those studies mostly evaluated increases in mean dosage per given time period as a measure of dose escalation.

Poor adherence has been linked to suboptimal patient outcomes across chronic diseases, including IA, ${ }^{3425}$ and biological therapy is no exception from this relationship. A study by Bluett et at and Blume et a $\hat{l}^{36}$ showed that patients who were ever non-adherent to their SC-TNFi were significantly less likely to achieve a good European League Against Rheumatism response and significantly more likely to have no response after 6 months of treatment.

The limitations of this study are as follows. First, as the clinical data were unavailable from the administrative database, the treatment cohorts were not matched for patient and clinical characteristics; meaning that there could be other unmeasured factors that would drive use and adherence patterns associated with each medication. Indeed, the proportion of patients with RA, AS and PsA in each cohort cannot be ascertained. The selection of a 24 months' period on therapy also could lead to a channelling bias and preselect patients with better adherence and overall response to therapy. An additional limitation for the data source is the fact that it may include administrative coding errors. Finally, one could argue that pharmacy refills do not necessarily mean that the medication was in fact taken by a patient.

In conclusion, this real-life study evaluating adherence to SC-TNFis in IA using data from the Canadian administrative databases, demonstrates considerably high adherence rates with SC-TNFis. However, GLM was found to have better adherence compared with the other SC-TNFis, which could, in part, be the result of a simpler, less frequent dosing regimen. Further studies are needed to investigate the reasons for the difference in adherence between golimumab and other SC-TNFis and to evaluate the impact of this improved adherence on clinical and health-economic outcomes.

Contributors $\mathrm{PB}$ was involved in the design and acquisition; $\mathrm{PB}, \mathrm{FN}$ and $\mathrm{KM}$ in the analysis; PB, MJB, LB, CT, FN and KM in the interpretation and FN and KM in the writing.
Funding This study was funded by Janssen, Canada funded this study. PB, KM, CT and FN are employees of Janssen, Canada. Study sponsors assisted with study design, interpretation of results and manuscript development.

Competing interests PB, CT, FN and KM are (were) employees of Janssen when the study was executed.

Provenance and peer review Not commissioned; externally peer reviewed.

Data sharing statement The raw data used for this study can be obtained by contacting the owner of the database (IMS Health Consulting). The analysis report used for this manuscript can be provided by communicating with FN.

Open Access This is an Open Access article distributed in accordance with the Creative Commons Attribution Non Commercial (CC BY-NC 4.0) license, which permits others to distribute, remix, adapt, build upon this work non-commercially, and license their derivative works on different terms, provided the original work is properly cited and the use is non-commercial. See: http://creativecommons.org/ licenses/by-nc/4.0/

(c) Article author(s) (or their employer(s) unless otherwise stated in the text of the article) 2017. All rights reserved. No commercial use is permitted unless otherwise expressly granted.

\section{REFERENCES}

1. Bykerk VP, Akhavan P, Hazlewood GS, et al. Canadian Rheumatology Association recommendations for pharmacological management of rheumatoid arthritis with traditional and biologic disease-modifying antirheumatic drugs. J Rheumatol 2012;39:1559-82.

2. Rohekar S, Chan J, Tse SML, et al. 2014 Update of the Canadian Rheumatology Association/Spondyloarthritis Research Consortium of Canada Treatment Recommendations for the Management of Spondyloarthritis. Part I: Principles of the Management of Spondyloarthritis in Canada. J Rheumatol 2015;42:654-64.

3. Viller F, Guillemin F, Briançon S, et al. Compliance to drug treatment of patients with rheumatoid arthritis: a 3 year longitudinal study. $J$ Rheumatol 1999;26:2114-22.

4. Bluett J, Morgan C, Thurston L, et al. Impact of inadequate adherence on response to subcutaneously administered anti-tumour necrosis factor drugs: results from the Biologics in Rheumatoid Arthritis Genetics and Genomics Study Syndicate cohort. Rheumatology 2015;54:494-9.

5. Osterberg L, Blaschke T. Adherence to medication. N Engl J Med 2005;353:487-97.

6. van den Bemt BJ, Zwikker HE, van den Ende $\mathrm{CH}$. Medication adherence in patients with rheumatoid arthritis: a critical appraisal of the existing literature. Expert Rev Clin Immunol 2012;8:337-51.

7. Borah BJ, Huang X, Zarotsky V, et al. Trends in RA patients' adherence to subcutaneous anti-TNF therapies and costs. Curr Med Res Opin 2009;25:1365-77.

8. Curkendall S, Patel V, Gleeson M, et al. Compliance with biologic therapies for rheumatoid arthritis: do patient out-of-pocket payments matter? Arthritis Rheum 2008;59:1519-26.

9. Li P, Blum MA, Von Feldt J, et al. Adherence, discontinuation, and switching of biologic therapies in medicaid enrollees with rheumatoid arthritis. Value Health 2010;13:805-12.

10. Tkacz J, Ellis L, Bolge SC, et al. Utilization and adherence patterns of subcutaneously administered anti-tumor necrosis factor treatment among rheumatoid arthritis patients. Clin Ther 2014;36:737-47.

11. Steiner JF, Koepsell TD, Finn SD, et al. A general method of compliance assessment using centralized pharmacy records. Description and validation. Med Care 1988;26:814-23.

12. Steiner JF, Prochazka AV. The assessment of refill compliance using pharmacy records: methods, validity, and applications. J Clin Epidemiol 1997;50:105-16.

13. Harrold LR, Andrade SE, Briesacher BA, et al. Adherence with urate-lowering therapies for the treatment of gout. Arthritis Res Ther 2009;11:R46.

14. Sikka R, Xia F, Aubert RE. Estimating medication persistency using administrative claims data. Am J Manag Care 2005;11:449-57.

15. Valenstein M, Copeland LA, Blow FC, et al. Pharmacy data identify poorly adherent patients with schizophrenia at increased risk for admission. Med Care 2002;40:630-9.

16. Wade SW, Satram-Hoang S, Nadkar A, et al. Impact of medication adherence on health care utilization and productivity: self-reported data from a cohort of postmenopausal women on osteoporosis therapy. Clin Ther 2011;33:2006-15. 
17. Zhang Y, Lave JR, Donohue JM, et al. The impact of Medicare Part D on medication adherence among older adults enrolled in MedicareAdvantage products. Med Care 2010;48:409-17.

18. Watanabe $\mathrm{JH}$, Bounthavong $\mathrm{M}$, Chen $\mathrm{T}$. Revisiting the medication possession ratio threshold for adherence in lipid management. Curr Med Res Opin 2013;29:175-80.

19. SIMPONI® (Golimumab) Product Monograph. Janssen Inc, 2014:124.

20. CIMZIA® (Certolizumab pegol) Product Monograph. UCB Canada Inc, 2014:54.

21. ENBREL $®$ (Etanercept) Product Monograph. Amgen Canada Inc, 2015:87.

22. HUMIRA ${ }^{\circledR}$ (Adalimumab) Product Monograph. AbbVie Corp, 2016:141

23. Harrold LR, Andrade SE. Medication adherence of patients with selected rheumatic conditions: a systematic review of the literature. Semin Arthritis Rheum 2009;38:396-402.

24. Benjamin RM. Medication adherence: helping patients take their medicines as directed. Public Health Rep 2012;127:2-3.

25. Contreras-Yáñez I, Ponce De León S, Cabiedes J, et al. Inadequate therapy behavior is associated to disease flares in patients with rheumatoid arthritis who have achieved remission with diseasemodifying antirheumatic drugs. Am J Med Sci 2010;340:282-90.

26. Fischer MA, Stedman MR, Lii J, et al. Primary medication nonadherence: analysis of 195,930 electronic prescriptions. J Gen Intern Med 2010;25:284-90.

27. Grijalva CG, Chung CP, Arbogast PG, et al. Assessment of adherence to and persistence on disease-modifying antirheumatic drugs (DMARDs) in patients with rheumatoid arthritis. Med Care 2007;45(10 Supl 2):S66-S76.

28. Granger AL, Fehnel SE, Hogue SL, et al. An assessment of patient preference and adherence to treatment with Wellbutrin SR: a webbased survey. J Affect Disord 2006;90:217-21.

29. Kendler D, Kung AW, Fuleihan G-H, et al. Patients with osteoporosis prefer once weekly to once daily dosing with alendronate. Maturitas 2004;48:243-51.

30. Reginster JY, Rabenda V, Neuprez A. Adherence, patient preference and dosing frequency: understanding the relationship. Bone 2006;38(4 Suppl 1):S2-S6.
31. Coleman $\mathrm{Cl}$, Limone B, Sobieraj DM, et al. Dosing frequency and medication adherence in chronic disease. J Manag Care Pharm 2012;18:527-39.

32. Iskedjian M, Einarson TR, MacKeigan LD, et al. Relationship between daily dose frequency and adherence to antihypertensive pharmacotherapy: evidence from a meta-analysis. Clin Ther 2002:24:302-16.

33. Saini SD, Schoenfeld P, Kaulback K, et al. Effect of medication dosing frequency on adherence in chronic diseases. Am J Manag Care 2009;15:e22-33.

34. Smolen JS, Kay J, Doyle MK, et al. Golimumab in patients with active rheumatoid arthritis after treatment with tumour necrosis factor alpha inhibitors (GO-AFTER study): a multicentre, randomised, double-blind, placebo-controlled, phase III trial. Lancet 2009;374:210-21.

35. Bartelds GM, Krieckaert CL, Nurmohamed MT, et al. Development of antidrug antibodies against adalimumab and association with disease activity and treatment failure during long-term follow-up. JAMA 2011;305:1460-8.

36. Blume SW, Fox KM, Joseph G, et al. Tumor necrosis factor-blocker dose escalation in rheumatoid arthritis patients in a pharmacy benefit management setting. Adv Ther 2013;30:517-27.

37. Bonafede MM, Gandra SR, Fox KM, et al. Tumor necrosis factor blocker dose escalation among biologic naïve rheumatoid arthritis patients in commercial managed-care plans in the 2 years following therapy initiation. J Med Econ 2012;15:635-43.

38. Fisher MD, Watson C, Fox KM, et al. Dosing patterns of three tumor necrosis factor blockers among patients with rheumatoid arthritis in a large United States managed care population. Curr Med Res Opin 2013;29:561-8

39. Moots RJ, Ostor AJ, Loft AG, et al. Reduction of direct and indirect costs in patients with AS receiving etanercept: results from an openlabel 36-week extension of the ASCEND study in four European countries. Rheumatology 2012;51:393-6.

40. Ollendorf DA, Klingman D, Hazard E, et al. Differences in annual medication costs and rates of dosage increase between tumor necrosis factor-antagonist therapies for rheumatoid arthritis in a managed care population. Clin Ther 2009;31:825-35. 